Article

\title{
A Finite Element Analysis Model for Partial Discharges in Silicone Gel under a High Slew Rate, High-Frequency Square Wave Voltage in Low-Pressure Conditions
}

\author{
Moein Borghei and Mona Ghassemi *(1) \\ Department of Electrical and Computer Engineering, Virginia Polytechnic Institute and State University, \\ Blacksburg, VA 24061, USA; moeinrb@vt.edu \\ * Correspondence: monag@vt.edu
}

Received: 19 March 2020; Accepted: 23 April 2020; Published: 1 May 2020

check for updates

\begin{abstract}
Wide bandgap (WBG) devices made from materials such as $\mathrm{SiC}, \mathrm{GaN}, \mathrm{Ga}_{2} \mathrm{O}_{3}$ and diamond, which can tolerate higher voltages and currents compared to silicon-based devices, are the most promising approach for reducing the size and weight of power management and conversion systems. Silicone gel, which is the existing commercial option for encapsulation of power modules, is susceptible to partial discharges (PDs). PDs often occur in air-filled cavities located in high electric field regions around the sharp edges of metallization in the gel. This study focuses on the modeling of PD phenomenon in an air filled-cavity in silicone gel for the combination of (1) a fast, high-frequency square wave voltage and (2) low-pressure conditions. The low-pressure condition is common in the aviation industry where pressure can go as low as $4 \mathrm{psi}$. To integrate the pressure impact into PD model, in the first place, the model parameters are adjusted with the experimental results reported in the literature and in the second place, the dependencies of various PD characteristics such as dielectric constant and inception electric field on pressure are examined. Finally, the reflections of these changes in PD intensity, duration and inception time are investigated. The results imply that the low pressure at high altitudes can considerably affect the PD inception and extinction criterion, also the transient state conditions during PD events. These changes result in the prolongation of PD events and more intense ones. As the PD model is strongly dependent upon the accurate estimation electric field estimation of the system, a finite-element analysis (FEA) model developed in COMSOL Multiphysics linked with MATLAB is employed that numerically calculates the electric field distribution.
\end{abstract}

Keywords: finite-element analysis model; high frequency; high slew rate; low-pressure condition; partial discharge; silicone gel

\section{Introduction}

In the commercial aircraft segment, the annual growth in global air traffic passenger demand is expected at $4.7 \%$ until 2028 [1] with passenger numbers expected to double in the next 20 years until around 2040 [2]. However, the commercial aviation industry will have to face both economic and environmental issues. In 2017, the U.S. commercial aviation consumed the equivalent of about $16 \%$ by volume of petroleum (crude oil and products) imports [3]. In the same year, air travel accounted for about 174.8 million metric tons of $\mathrm{CO}_{2}$ equivalent emissions in the U.S. or about $2.6 \%$ of domestic greenhouse gas emissions [4]. To decarbonize and reduce energy consumption, enabling technologies for electrified aircraft propulsion have been targeted. In this regard, wide bandgap (WBG)-based drives are a promising solution to achieve high power density and efficiency simultaneously for all-electric powertrain. 
One of the merits of WBG devices is that their slew rates and switching frequencies are much higher than that of Si-based devices. However, frequency and slew rate are two of the most critical factors of a voltage pulse, influencing the level of degradation of the insulation systems exposed to such pulses. A critical review of the accelerated insulation aging issue in different electrification components such as electrical motors, transformers, cables and solid-state transformers, identifying technical gaps and future research needs, has recently been carried out in Reference [5] where it was identified that partial discharge (PD) has the largest effect on insulation degradation.

Two common insulation materials used in power electronic modules are ceramic substrate and silicone gel. As the main insulation system, ceramic substrate ensure electrical insulation between active components and the baseplate, which is generally grounded. Silicone gel is used for encapsulation to prevent in situ electrical discharges in air and to protect substrates, semiconductors and connections against humidity, dirt and vibration. Although alternatives have been researched [6-8], silicone gel, which is a weaker insulator than dielectric ceramics and more vulnerable to PDs, is still the only option for encapsulation of WBG power modules. A thorough and in-depth review of PD measurements, failure analyses and control in high-power Si-Insulated-gate bipolar transistor (IGBT) modules has been done in $[9,10]$.

Solid and liquid dielectrics often contain cavities or voids within the dielectric material or on the boundaries between the insulating material and the electrodes. Besides, air-filled voids may also form due to different degradation mechanisms over the lifetime of insulators. These cavities usually vanish quickly after their formation in non-viscous liquids but in the case of silicone gel, an air-filled cavity can last up to $10 \mathrm{~ms}$ that is 1000 times longer than that of non-viscous liquids [11]. PDs during this time may lead to the gradual degradation of silicone gel. Recently a combination of geometrical techniques and applying nonlinear resistive grading layers to high field regions have been proposed [12-20]. In this regard, the elucidation and understanding of mechanisms and factors behind PD can help to utilize such electric field control methods better.

To date, four major PD models have been introduced to represent a cavity-dielectric system; in the order of their introduction date, the models are three-capacitance (abc), induced charge concept (ICC), finite element analysis (FEA) and Multiphysics models. The abc model firstly introduced by Whitehead used an analogue circuit consisting of three capacitances for modeling the cavity, the insulation in series with the cavity and the remaining insulation. Despite providing a relatively simple model, it gives a perception of PD mechanism from a macroscopic point of view. However, the inability of the model to validly represent physics behind PD has been enumerated as one of the major disadvantages of the abc model [21].

Pedersen et al. later proposed an analytical model in which the concept of induced charge on the electrode was used to explain the partial discharge transients [21,22]. While the analytical model gave more explanations on the physical process behind $\mathrm{PD}$, it could be too complicated to be applied to more sophisticated geometries. Moreover, the assumptions made for simplification have aroused serious questions on the validity of the model; for example, the assumption that system capacitance remains unaffected by PD later was rejected in Reference [23].

On the other hand, although Multiphysics models [24,25] may be able to accurately model mechanisms and phenomena associated with PDs, there are many physical parameters in the model that need to be experimentally determined. Adjusting these physical parameters to meet PD measurements for a specific testing geometry and dimension may not always be able to be generalized.

The availability of advanced computational tools has enabled the utilization of numerical methods including Finite Difference Method (FDM), Finite Element Method (FEM) and Charge Simulation Method (CSM). Using these methods, one can numerically estimate the electric field intensity in the cavity-dielectric system. As will be shown later, almost all the aspects of PD phenomenon are related to electric field distribution and intensity; therefore, an accurate estimate of the electric field can pave the road for understanding and quantification of the PD characteristics. A comparison between ICC and FEA models is made in Reference [26]. Thanks to the availability of high-performance computers 
as well as COMSOL Multiphysics and MATLAB, this study takes advantage of FEA to investigate the PD phenomenon.

In Reference [27], the detrimental impact of slew rate was studied and the results showed that high slew rate square voltages substantially increased the intensity of PDs within the insulating medium and changed the PD behavior over time, that is, the repetition rate and the times at which discharges occur. It has also been shown in References $[28,29]$ that, although at a higher frequency the PD intensity is lower, the higher repetition rate causes rapid degradation of insulation. Thus, at higher frequencies, the lifetime of insulation is reduced. In Reference [30], the simulation of partial discharge is performed for square wave voltage, however, the applied voltage frequency is only $200 \mathrm{~Hz}$. In Reference [31], the results of tests on single-point contact crossed pairs are reported to assess the impact of rise-time ( $200 \mathrm{~ns}$ to $400 \mu \mathrm{s}$ ) on PD intensity and frequency spectrum. The results indicated that high-frequency components proliferate in the PD spectrum of energy at low slew rates of square wave voltage. The authors further extended their studies toward the impact of high frequency (up to $5 \mathrm{kHz}$ ) voltage pulses on the motor insulation life [29] and it is shown that the physical and chemical deterioration rate of insulation is influenced at higher frequencies. While the reported experimental results provided invaluable clues on the impact of fast-rise, high-frequency square wave voltages, no study has been performed on the modeling of PD phenomenon under this type of voltage. To address this gap, a FEA method was developed in Reference [28] for modeling PD characteristics under fast, repetitive voltage pulses.

Aside from the impact of the applied voltage characteristics, environmental conditions can also change the way the PD phenomenon is looked at today. For instance, an aircraft can be at a pressure as low as 4 psi when flying at cruising altitude where the impact of pressure on PD occurrence has not been sufficiently studied so far. To the best of our knowledge, little research appears on the effect of fast, repetitive voltage pulses at low-pressure levels on PD behavior. For example, in Reference [32] test results under square wave voltages with frequencies in $5-200 \mathrm{kHz}$ range at pressure levels between 20 and $100 \mathrm{kPa}$ implied that the PD inception voltage is constantly decreasing with pressure.

This study focuses on the effects that low-pressure conditions have on different model parameters and reflects on how these changes affect PD characteristics. The work was done under high frequency, high slew rate voltages to accurately model the escalated tension that the insulation system undergoes. This paper takes advantage of the FEA model for the above goal. The advantages of FEA over other models are its ability to apply to sophisticated geometries as well as its ability to dynamically monitor changes in the values of electrical properties such as electric field, current density, field displacement and so forth [33].

In Section 2, the effect of pressure on PD inception, extinction and dielectric constant is analyzed. In Section 3, PD modeling details are discussed. Section 4 is dedicated to a case study where the proposed modeling is applied and the results are discussed. Section 5 gives conclusions.

\section{Impact of Pressure}

\subsection{PD Inception}

A discharge occurs when a collision takes place between free electrons and other atoms/molecules, giving rise to an electron avalanche. The existence of at least one free electron is necessary for ionization to occur. Besides, the electric field should be high enough to energize the electrons when colliding with other particles.

In Reference [21], a critical number of electrons at the avalanche head that could guarantee the self-propagation of the ionization process was proposed. For an ellipsoidal void, the mentioned condition known as streamer inception criterion can be described as:

$$
E_{i n c}=(E / p)_{c r} p\left(1+\frac{B}{(p l)^{n}}\right)
$$


In the above expression, $(E / p)_{c r}, B$ and $n$ are gas parameters. In air, their values are $24.2 \mathrm{VPa}^{-1} \mathrm{~m}^{-1}$, $8.6 \mathrm{~Pa}^{0.5} \mathrm{~m}^{0.5}$ and 0.5 , respectively. The pressure of air is denoted as $p$, while $l$ represents the ellipsoidal cavity diameter in the direction of electric field.

\subsection{PD Extinction}

Discharge occurs through an increase in the cavity conductivity from an initial value (approximately zero) to a higher value $\left(\sigma_{c a v}, \max \right)$. An increase in conductivity results in a decrease in the electric field intensity inside the cavity. Conductivity remains at a high value until the electric field recedes to a certain magnitude, called the Extinction Electric Field $\left(E_{\text {ext }}\right)$. According to Gutfleisch and Niemeyer [34,35], the electric field at which PD is quenched can be described as a function of the critical electric field:

$$
E_{e x t}=\gamma p(E / p)_{c r}
$$

In the above expression, $\gamma$ is a dimensionless factor varying with the change of voltage polarity. $\gamma$ is experimentally adjusted for the normal temperature and pressure (NTP) conditions $\left(p_{0}, T_{0}\right)$.

\subsection{Dielectric Constant (Relative Permittivity)}

As this study strives to model partial discharge throughout changes in pressure magnitude, it is crucial to take into account the effect of pressure on relative permittivity. The reason for this is that the dielectric constant can change the magnitude of the electric field according to the Maxwell equation and PD modeling is strongly dependent upon the accurate estimation of electric field distribution.

Owen and Brinkley suggested that the relative permittivity of a liquid dielectric can be given by Reference [36]:

$$
1-\frac{\epsilon_{p_{0}}}{\epsilon_{p}}=A \ln \left(\frac{B+p}{B+p_{0}}\right),
$$

where $\epsilon_{p_{0}}$ and $p_{0}$ denote the relative permittivity and pressure, respectively, under NTP conditions. Similarly, $\epsilon_{p}$ stands for the relative permittivity at pressure $p$. $A$ and $B$ are constants of Tait expression related to the material and must be experimentally determined. Thus, in this study, approximate values are derived from Reference [37]. This expression takes only pressure into account. However, the author mentions that parameter $A$ is independent of temperature and $B$ is often decreasing with temperature.

Since silicone gel has properties of liquid dielectrics in terms of viscosity, in this paper, we assume that (3) can be used for silicone gel as well. In this regard, Figure 1 shows the changes in silicone gel relative permittivity as a function of pressure. Generally, the figure implies that the relative permittivity has a direct relationship with pressure; however, the rate of change declines as pressure is reduced and $\epsilon_{r}$ has little variations for $p<1 \mathrm{~atm}$.

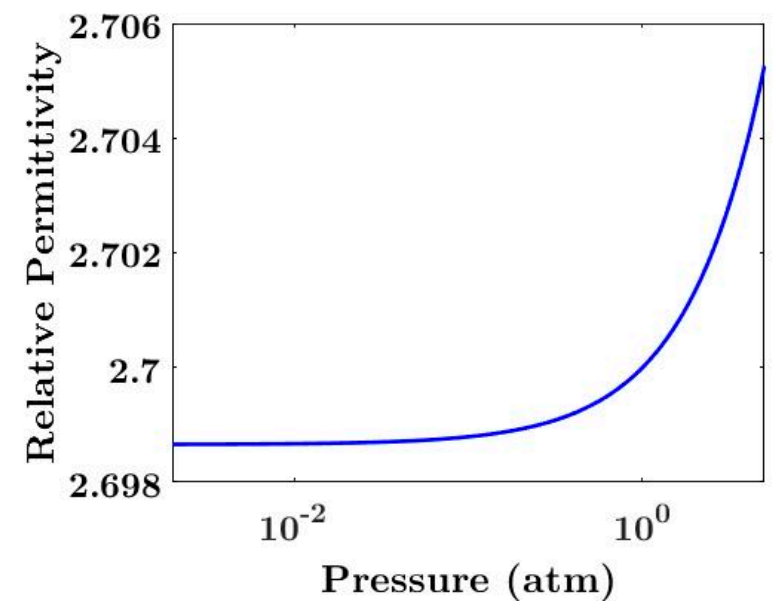

Figure 1. The relative permittivity of silicone gel as a function of pressure. 


\section{PD Modeling}

As disclosed earlier, the electric field intensity plays a major role in different sections of PD modeling. Therefore, an accurate estimation of the electric field distribution is crucial to the whole process. In this regard, the current study employs FEA to utilize the capabilities of the finite-element method to accurately estimate the electric field distribution within the air filled-cavity, silicone gel system.

In this work, COMSOL Multiphysics is used to implement FEA. Therefore, the electric current (ec) interface of COMSOL Multiphysics is used in a time-dependent mode. The boundary conditions include the setting of the high-voltage electrode boundary to the applied voltage waveform and the ground electrode boundary to zero voltage. Another condition is that no current flows into the boundary that is not included in the aforementioned boundary conditions.

LiveLink $^{\mathrm{TM}}$ for MATLAB is also used along with COMSOL to model the other parts of the algorithm such as checking conditionals within the PD model and calculating the true and apparent charge magnitudes. Moreover, the interface also plays a role in the analysis of the PD sensitivity to the affecting parameters.

To calculate the true and apparent charge magnitudes, the algorithm uses one of the outputs of COMSOL, which is the current density flowing through the cavity wall and ground electrode. Then, by integrating the current density over time, starting from inception and going to extinction, the charge magnitudes are obtained.

The PD modeling process is shown in Figure 2. Starting from the beginning of the period, the PD prerequisites are examined at each time step $\left(\Delta t_{H}\right)$. Before the occurrence of a PD event, the cavity conductivity is set to its initial value $\left(\sigma_{c a v}, 0\right)$. The electric field distribution is obtained for each time step by FEA model to evaluate the PD occurrence requirements (i.e., streamer inception criterion and the availability of initial free electron).

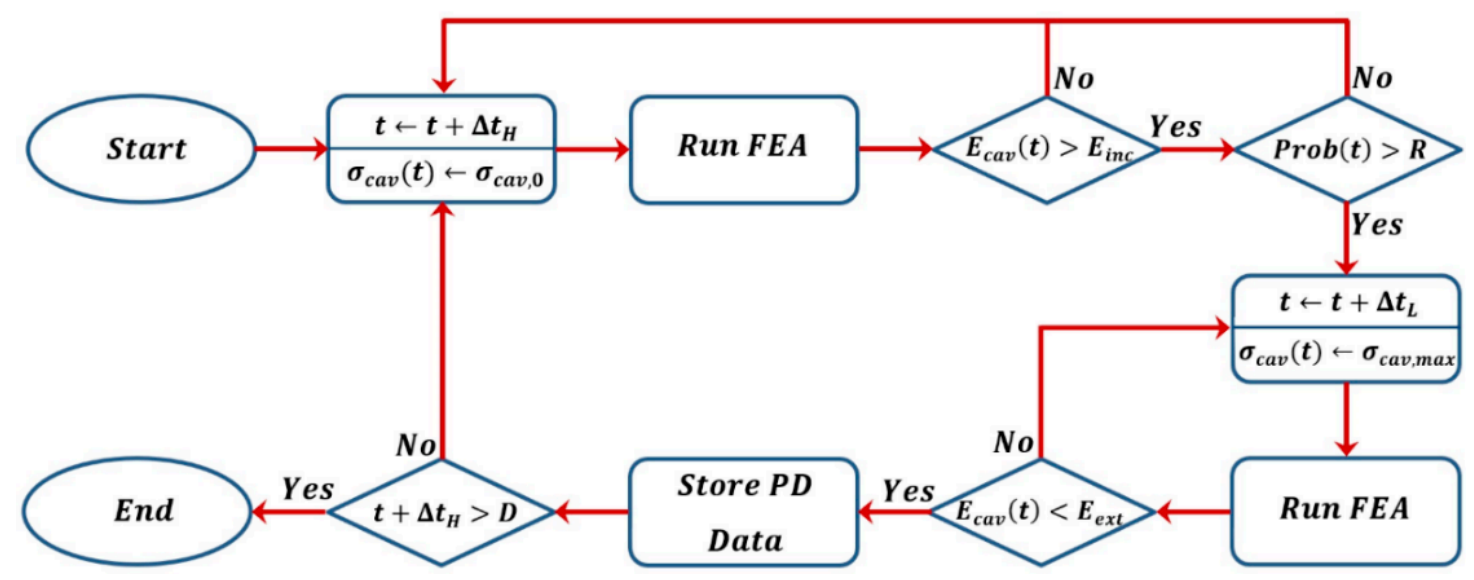

Figure 2. The flowchart of the partial discharge (PD) modeling procedure.

If any of the requirements are not met, the process adds a time step $\left(\Delta t_{H}\right)$ to the time until reaching a moment that both PD conditions are met or the process reaches the end of the time. For the times that the occurrence of PD is confirmed, the conductivity of the cavity is enhanced as explained earlier. In the next time steps $\left(\Delta t_{L}\right)$, the PD extinction is looked for after running FEA.

The time steps referred to during this algorithm vary according to the state of the process. As the changes during PD are in order of nanoseconds, the time step during $\operatorname{PD}\left(\Delta t_{L}\right)$ is much smaller than the time step during no-PD $\left(\Delta t_{H}\right)$ period.

\section{Results and Key Challenges}

The geometry that was examined for the modeling and simulations is shown in Figure $3 \mathrm{a}$ and consists of two spherical electrodes; one is the high-voltage electrode while the other is grounded, 
both made of copper. The two spheres are situated within a cylindrical block of silicone gel $\left(\varepsilon_{r}=2.7\right.$ at NTP) with a spherical air-filled cavity inside. The geometric parameters of the void-dielectric set are shown in Table 1. This geometry with silicone gel as its dielectric material was first proposed and tested in Reference [38]. The authors in their previous work [28], estimated the parameters associated with PD model such that it reproduces the same results as in Reference [38] and chose it as a solid groundwork for further investigations. Due to the symmetry of this configuration, it can be also demonstrated in a 2D-axisymmetrical format as shown in Figure 3b. Using the 2D demonstration instead of a 3D figure significantly reduces FEA calculation burden.

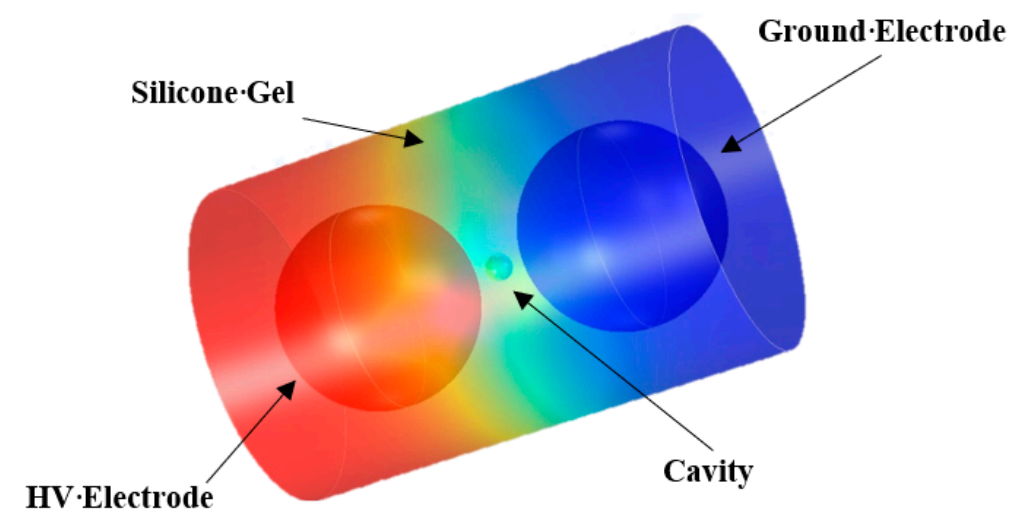

(a)

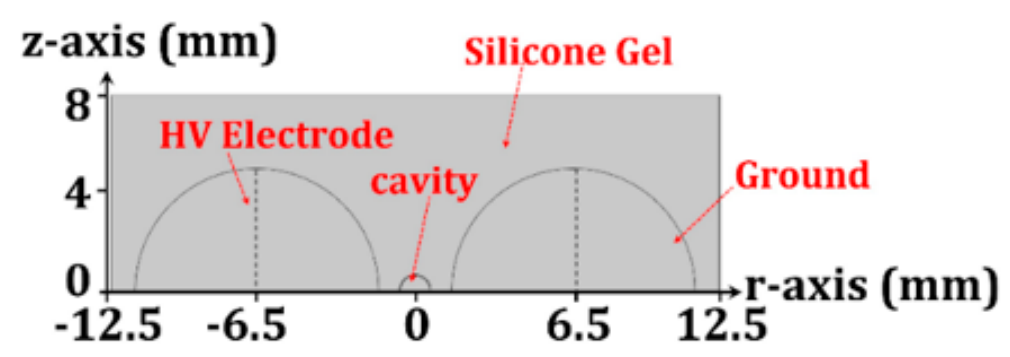

(b)

Figure 3. The (a) 3D and (b) 2D axisymmetrical geometry of the case study.

Table 1. Dimensions of the Case Study.

\begin{tabular}{ccccc}
\hline Parameter & Dielectric Block Height & Dielectric Radius & Cavity Diameter & Electrode Diameter \\
\hline Value & $25 \mathrm{~mm}$ & $8 \mathrm{~mm}$ & $1.2 \mathrm{~mm}$ & $10 \mathrm{~mm}$ \\
\hline
\end{tabular}

The properties of the unipolar square wave voltage are shown in Table 2.

Table 2. Unipolar Square Wave Voltage Parameters.

\begin{tabular}{ccccc}
\hline Parameter & $\mathbf{U}_{\max }$ & $f$ & Rise Time & Duty Cycle \\
\hline Value & $18 \mathrm{kV}$ & $10 \mathrm{kHz}$ & $50 \mathrm{~ns}$ & $50 \%$ \\
\hline
\end{tabular}

Figure 4 demonstrates that $E_{i n c}$ and $E_{\text {ext }}$ have opposite trends with pressure variation. $E_{\text {inc }}$ is a decreasing function of pressure, while $E_{\text {ext }}$ is an increasing function. As will be shown later, these two trends play a significant role in PD characteristics such as PD inception and extinction times, intensity and so forth. 


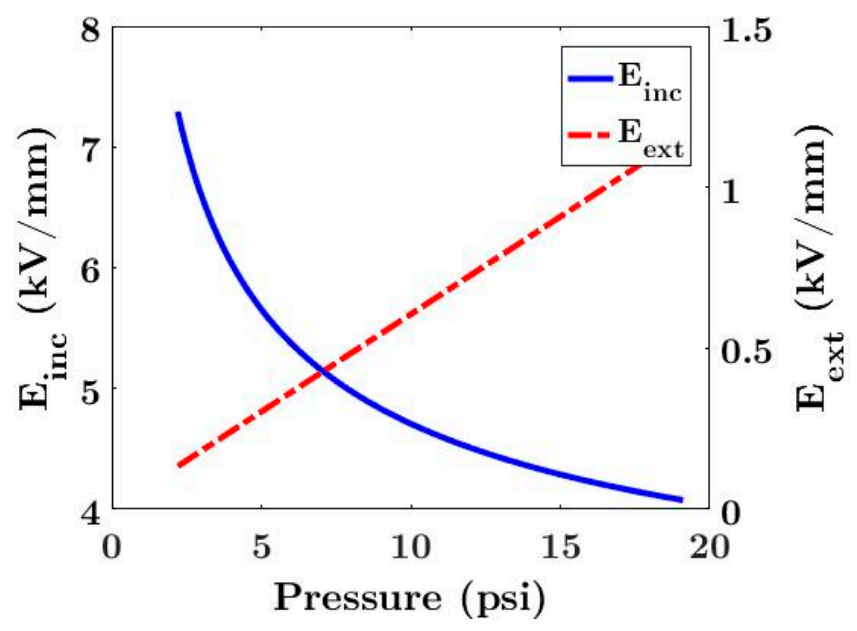

Figure 4. The PD inception and extinction electric fields versus pressure.

The rest of this section focuses on the variations of several PD characteristics with pressure. Simulations are performed for 15 pressure values which are shown in red points in Figures 5-7. Then, the trends of the variations denoted as a fitted curve in Figures 5-7 are derived over a continuous range of pressures using smoothing spline interpolation technique.

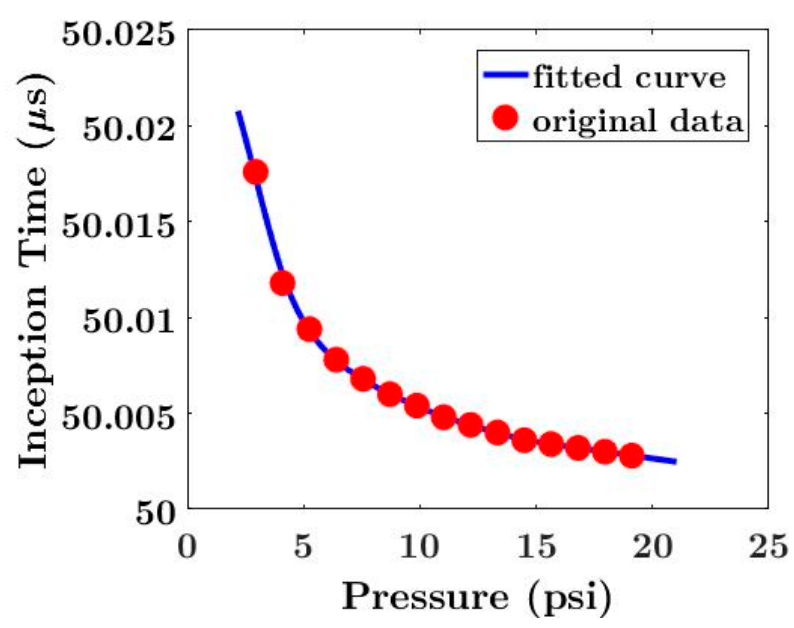

Figure 5. The impact of pressure on PD inception time.

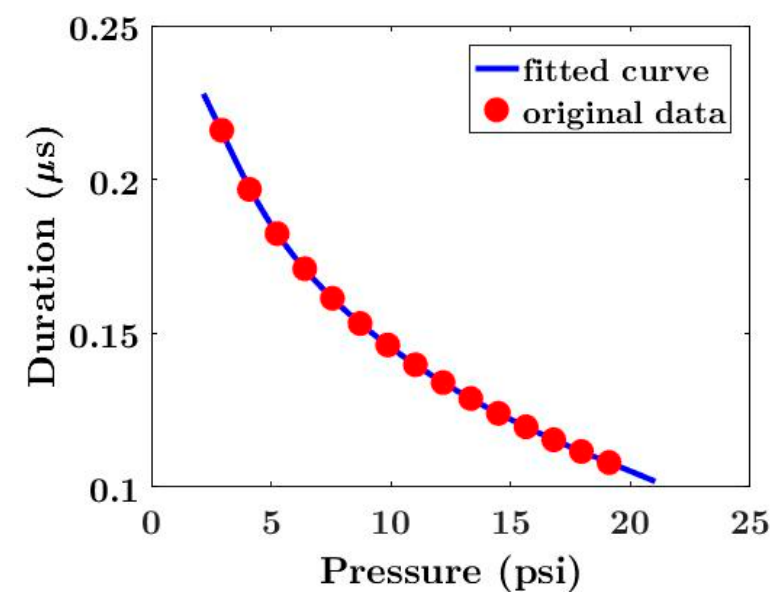

Figure 6. The relationship between PD duration and pressure. 


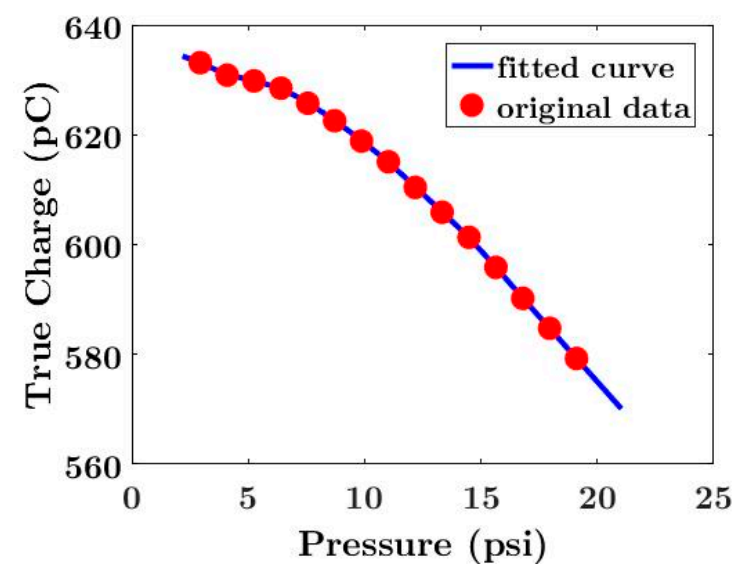

Figure 7. Variations of PD true charge as a function of pressure.

Figure 5 reflects the impact of pressure on the inception time of PDs. Higher inception time values at lower pressures can be explained by the fact that as the pressure decreases, $E_{\text {inc }}$ goes up. As $E_{\text {inc }}$ increases, the PD demands more time to catch a higher electric field value. A quick conclusion might be that the later PD occurs, the longer the insulation material can withstand degradation; however, as will be discussed next, a bit later discharges impose more intense ones.

Similarly, the extinction time trend can be justified; at lower pressures, the linear function of the extinction field, concerning pressure, trends downward as well. To quench a discharge at lower field magnitudes, more time in the high-conductivity period is needed to reduce the electric field intensity. Thus, like inception time, extinction time is also higher for lower pressures. Since both inception and extinction times increase with pressure reduction, what happens to the duration of PD at lower pressures? Figure 6 indicates that the duration of discharges at lower pressures are higher than NTP conditions. Thus, it can be inferred that, under low-pressure conditions, the prolongation of PDs due to later extinction times is much higher than the shortening of PDs due to later inception times. This difference tends to decline as the pressure goes up.

Figure 7 shows variations of PD true charge magnitude as a function of pressure. The results affirm that as the pressure is reduced, the PD magnitude increases. There are two different mechanisms that play different roles. One is that, at lower pressures, discharge occurs at higher field magnitudes; according to Ohm's law, at higher field magnitudes, the current density will be higher. A higher current density then leads to a higher discharge magnitude. On the other hand, the relative permittivity declines at lower pressures, which means that the field displacement would be lower $(D=\epsilon E)$. Since the field displacement has a direct relationship with the true charge magnitude, at a lower permittivity the amount of true charge would be lower. Figure 1 shows that the variations of relative permittivity at low pressures are not as sharp as at high pressures; hence, the overall increased magnitude of true charge is due to the deeper impact of $E_{i n c}$ enhancement versus $\epsilon_{r}$ reduction at low pressures.

\section{Conclusions}

The growing trend toward the electrification of the aviation industry urges the demand for ensuring the reliability of the insulation system. The utilization of WBG-based power modules can impose further threats to the insulation systems due to their operation at a higher frequency and higher slew rate. Because the pressure at higher altitudes can be extremely low, this study examined the impact of high frequency, high slew rate unipolar square wave voltage under low-pressure conditions. It was shown that low-pressure conditions have a game-changing impact by influencing the PD inception and extinction times, duration and intensity. These changes are the result of changes in the inception and extinction electric fields as well as the relative permittivity of the insulation medium. The results show that despite a slight delay in PD initiation under low-pressure conditions, the true charge magnitude is increased by about $20 \%$ and the duration of PD events is nearly doubled at cruise altitude compared 
to the ground level. As the material nature has a substantial impact on the extent and nature of the aforementioned changes, more research on different insulating materials can lead to the development of a more reliable insulation system under extremely low-pressure conditions.

Author Contributions: The authors contributed equally to this work in all parts. All authors have read and agreed to the published version of the manuscript.

Funding: This material is based upon work supported by the Air Force Office of Scientific Research under award number FA9550-20-1-0033.

Conflicts of Interest: The authors declare no conflict of interest.

\section{References}

1. Advisory Council for Aeronautics Research in Europe. Aeronautics and Air Transport: Beyond Vision 2020 (Towards 2050); Publications Office of the EU: Brussels, Belgium, 2010.

2. Advisory Council for Aeronautics Research in Europe. Strategic Research \& Innovation Agenda-2017 Update; ACARE: Brussels, Belgium, 2017.

3. U.S. Environmental Protection Agency (EPA): Fast Facts on Transportation Greenhouse Gas Emissions. 2019. Available online: https://www.epa.gov/greenvehicles/fast-facts-transportation-greenhouse-gas-emissions (accessed on 15 June 2019).

4. U.S. Energy Information Administration (EIA): Monthly Energy Review. 2020. Available online: https: //www.eia.gov/totalenergy/data/monthly/pdf/sec3_9.pdf (accessed on 15 March 2020).

5. Ghassemi, M. Accelerated Insulation Aging due to Fast, Repetitive Voltages: A Review Identifying Challenges and Future Research Needs. IEEE Trans. Dielectr. Electr. Insul. 2019, 26, 1558-1568. [CrossRef]

6. Muslim, D.J.; Lesaint, O.; Hanna, R.; Reboud, J.L.; Sinisuka, N.I. Electrical characterization of Dibenzyltoluene liquid at high temperatures up to 350_C. In Proceedings of the IEEE Annual Report Conference on Electrical Insulation and Dielectric Phenomena. (CEIDP), Cancun, Mexico, 21-24 October 2018; pp. 58-61.

7. Muslim, J.; Lesaint, O.; Hanna, R.; Sinisuka, N.I. Streamer generation and propagation in Dibenzyltoluene and Ester liquids under high temperature. In Proceedings of the IEEE International Conference Dielectric Liquids (ICDL), Roma, Italy, 23-27 June 2019; pp. 1-4.

8. Muslim, J.; Lesaint, O.; Hanna, R.; Sinisuka, N.I. Partial discharge measurements on Dibenzyltoluene for high temperature encapsulant application up to $350^{\circ} \mathrm{C}$. In Proceedings of the IEEE International Conference Dielectric Liquids (ICDL), Roma, Italy, 23-27 June 2019; pp. 1-4.

9. Ghassemi, M. PD Measurements, Failure Analysis and Control in High Power IGBT Modules. High. Volt. 2018, 3, 170-178. [CrossRef]

10. Ghassemi, M. Electrical insulation weaknesses in wide bandgap devices. In Simulation and Modelling of Electrical Insulation Weaknesses in Electrical Equipment; Albarracin, R., Ed.; InTechOpen: London, UK, 2018; pp. 129-149.

11. Wang, N.; Cotton, I.; Robertson, J.; Follmann, S.; Evans, K.; Newcombe, D. Partial Discharge Control in a Power Electronic Module Using High Permittivity Non-Linear Dielectrics. IEEE Trans. Dielectr. Electr. Insul. 2010, 17, 1319-1326. [CrossRef]

12. Tousi, M.M.; Ghassemi, M. Electric field control by nonlinear field dependent conductivity dielectrics characterization for high voltage power module packaging. In Proceedings of the IEEE International Workshop on Integrated Power Packaging (IWIPP), Toulouse, France, 24-26 April 2019; pp. 54-58.

13. Tousi, M.M.; Ghassemi, M. Nonlinear field dependent conductivity materials for electric field control within next-generation wide bandgap power electronics modules. In Proceedings of the 2019 IEEE Electrical Insulation Conference (EIC), Calgary, AB, Canada, 16-19 June 2019; pp. 63-66.

14. Tousi, M.M.; Ghassemi, M. The effect of type of voltage (sinusoidal and square waveform) and the frequency on the performance of nonlinear field-dependent conductivity coatings for electric field control in power electronic modules. In Proceedings of the IEEE Conference on Electrical Insulation and Dielectric Phenomena (CEIDP), Richland, DC, USA, 20-23 October 2019; pp. 601-604.

15. Tousi, M.M.; Ghassemi, M. Electrical insulation packaging for a $20 \mathrm{kV}$ high density wide bandgap power module. In Proceedings of the IEEE Energy Conversion Congress \& Exposition (ECCE), Baltimore, MD, USA, 29 September-3 October 2019; pp. 4162-4166. 
16. Tousi, M.M.; Ghassemi, M. Nonlinear resistive electric field grading in high-voltage, high-power wide bandgap power module packaging. In Proceedings of the IEEE Energy Conversion Congress \& Exposition (ECCE), Baltimore, MD, USA, 29 September-3 October 2019; pp. 7124-7129.

17. Tousi, M.M.; Ghassemi, M. Combined Geometrical Techniques and Applying Nonlinear Field Dependent Conductivity Layers to Address the High Electric Field Stress Issue in High Voltage High-Density Wide Bandgap Power Modules. IEEE Trans. Dielectr. Electr. Insul. 2020, 27, 305-313. [CrossRef]

18. Tousi, M.M.; Ghassemi, M. Characterization of Nonlinear Field Dependent Conductivity Layer Coupled with Protruding Substrate to Address High Electric Field Issue within High Voltage High-Density Wide Bandgap Power Modules. IEEE J. Emerg. Sel. Top. Power Electron. 2020, 8, 343-350. [CrossRef]

19. Tousi, M.M.; Ghassemi, M. Effects of Frequency and Temperature on Electric Field Mitigation Method via Protruding Substrate Combined with Applying Nonlinear FDC Layer in Wide Bandgap Power Modules. Energies 2020, 13, 2022. [CrossRef]

20. Ghassemi, M. Geometrical techniques for electric field control in (ultra) wide bandgap power electronics modules. In Proceedings of the IEEE Electrical Insulation Conference (EIC), San Antonio, TX, USA, 17-20 June 2018; pp. 589-592.

21. Crichton, G.C.; Karlsson, P.W.; Pedersen, A. Partial Discharges in Ellipsoidal and Spheroidal Voids. IEEE Trans. Electr. Insul. 1989, 24, 335-342. [CrossRef]

22. Pedersen, A.; Crichton, G.C.; McAllister, I.W. The Theory and Measurement of Partial Discharge Transients. IEEE Trans. Electr. Insul. 1991, 26, 487-497. [CrossRef]

23. Achillides, Z.; Danikas, M.G.; Kyriakides, E. Partial discharge modeling and induced charge concept: Comments and criticism of Pedersen's model and associated measured transients. IEEE Trans. Dielectr. Electr. Insul. 2017, 24, 1118-1122. [CrossRef]

24. Callender, G.; Tanmaneeprasert, T.; Lewin, P.L. Simulating Partial Discharge Activity in a Cylindrical Void Using a Model of Plasma Dynamics. J. Appl. Phys. 2019, 52, 169501. [CrossRef]

25. Callender, G.; Golosnoy, I.O.; Rapisarda, R.; Lewin, P.L. Critical Analysis of Partial Discharge Dynamics in Air Filled Spherical Voids. J. App. Phys. 2018, 51, 125601. [CrossRef]

26. Borghei, M.; Ghassemi, M.; Rodríguez-Serna, J.M.; Albarracín-Sánchez, R. A Finite Element Analysis and an Improved Induced Charge Concept for Partial Discharge Modeling. IEEE Trans. Power Del. 2020. accepted and to be published.

27. Borghei, M.; Ghassemi, M. Partial discharge finite element analysis under fast, repetitive voltage pulses. In Proceedings of the IEEE Electric Ship Technologies Symposium (ESTS), Arlington, VA, USA, 13-19 August 2019; pp. 324-328.

28. Borghei, M.; Ghassemi, M. Partial Discharge Analysis Under High-Frequency, Fast-Rise Square Wave Voltages in Silicone Gel: A Modeling Approach. Energies 2019, 12, 4543. [CrossRef]

29. Wang, P.; Cavallini, A.; Montanari, G.C. The Influence of Repetitive Square Wave Voltage Parameters on Enameled Wire Endurance. IEEE Trans. Dielectr. Electr. Insul. 2014, 21, 1276-1284. [CrossRef]

30. Illias, H.A.; Bakar, A.H.A.; Mokhlis, H.; Tunio, M.A.; Chen, G.; Lewin, P.L.; Ariffin, A.M. Simulation of partial discharge within a void under square waveform applied voltage. In Proceedings of the IEEE Conference on Electrical Insulation and Dielectric Phenomena (CEIDP), Montreal, QC, Canada, 14-17 October 2012; pp. 76-79.

31. Wang, P.; Cavallini, A.; Montanari, G.C.; Wu, G. Effect of Rise Time on PD Pulse Features under Repetitive Square Wave Voltages. IEEE Trans. Dielectr. Electr. Insul. 2013, 20, 245-254. [CrossRef]

32. Meyer, D.R.; Cavallini, A.; Lusuardi, L.; Barater, D.; Pietrini, G.; Soldati, A. Influence of Impulse Voltage Repetition Frequency on RPDIV in Partial Vacuum. IEEE Trans. Dielectr. Electr. Insul. 2018, 25, 873-882. [CrossRef]

33. Borghei, M.; Ghassemi, M. Finite element modeling of partial discharge activity within a spherical cavity in a solid dielectric material under fast, repetitive voltage pulses. In Proceedings of the IEEE Electrical Insulation Conference (EIC), Calgary, AB, Canada, 16-19 June 2019; pp. 34-37.

34. Niemeyer, L. A Generalized Approach to Partial Discharge Modeling. IEEE Trans. Dielectr. Electr. Insul. 1995, 2, 510-528. [CrossRef]

35. Gutfleisch, F.; Niemeyer, L. Measurement and Simulation of PD in Epoxy Voids. IEEE Trans. Dielectr. Electr. Insul. 1995, 2, 729-743. [CrossRef] 
36. Owen, B.B.; Brinkley, S.R. The Effect of Pressure upon the Dielectric Constants of Liquids. Phys. Rev. 1943, 64, 32-36. [CrossRef]

37. Schornack, L.G.; Eckert, C.A. Effect of Pressure on the Density and Dielectric Constant of Polar Solvents. J. Phys. Chem. 1970, 74, 3014-3020. [CrossRef]

38. Ebke, T.; Khaddour, A.; Peier, D. Degradation of silicone gel by partial discharges due to different defects. In Proceedings of the IEEE International Conference on Dielectric Materials, Measurements and Applications, Edinburgh, UK, 17-21 September 2000; pp. 202-207.

(C) 2020 by the authors. Licensee MDPI, Basel, Switzerland. This article is an open access article distributed under the terms and conditions of the Creative Commons Attribution (CC BY) license (http://creativecommons.org/licenses/by/4.0/). 